\title{
Design and Mechanical Properties of Steel-UHPC Lightweight Composite Decks
}

\author{
Yong Liu, ${ }^{1,2}$ Xin Zhang, ${ }^{2}$ Rong Liu, ${ }^{2}$ and Guorong Chen ${ }^{3}{ }^{3}$ \\ ${ }^{1}$ School of Civil Engineering, Central South University, Changsha 410075, China \\ ${ }^{2}$ Hunan Provincial Communications Planning, Survey \& Design Institution Co., Ltd., Changsha, China \\ ${ }^{3}$ Dongguan Communications Investment Group Co.Ltd., Dongguan 523000, China \\ Correspondence should be addressed to Guorong Chen; chengr93@163.com
}

Received 29 May 2021; Accepted 16 August 2021; Published 7 September 2021

Academic Editor: Suvash Paul

Copyright (C) 2021 Yong Liu et al. This is an open access article distributed under the Creative Commons Attribution License, which permits unrestricted use, distribution, and reproduction in any medium, provided the original work is properly cited.

Orthotropic steel decks (OSDs) have been widely used in long-span bridges due to their advantages of being lightweight, having high capacity, and allowing rapid construction. However, due to the insufficiency of local stiffness of OSD, fatigue cracking and pavement damage have been common problems of OSDs worldwide. It seriously affects the safety and durability of long-span bridges. Therefore, to solve this problem, this paper introduces an innovative steel ultrahigh-performance concrete (steel-UHPC) lightweight composite deck (LWCD). LWCD can reduce the fatigue stress of the conventional OSD by up to $80 \%$ and extend the fatigue life to twice the design requirements. Furthermore, engineering practices in China have proven that LWCD can effectively reduce manufacturing costs and maintenance costs throughout the whole life cycle of the structures. Thus, to provide references for design and maintenance of long-span bridges, this paper introduces the structural design, construction techniques, joint construction design, repair methods, and economic benefits of LWCD in detail. Furthermore, numerical simulations and laboratory tests are introduced in this paper to validate the superiority of LWCD.

\section{Introduction}

Orthotropic steel decks (OSDs) have become the preferred structures of main girders of long-span bridges in recent decades because OSDs have many advantages such as being lightweight, having high strength, allowing rapid construction [1-4]. The development of OSD started in the 1920s. American engineers first used steel plates riveted to steel beams as bridge decks in large movable bridges. In 1938, the American Institute of Steel Construction (AISC) named such kind of deck as "battle deck" because the deck felt like having the same strength as battleship [5]. In 1948, Dr. Cornelis, a German engineer from MAN, registered a patent called "Road bridges with flat plates." It marked the birth of modern OSD [6]. In 1950, OSD was first applied in the Mulheim Bridge in Cologne, Germany [7]. In 1963, the AISC issued the first design manual of OSD [8]. Later on, from 1960 to 1980, OSDs were widely used in developed countries, such as the US, Japan [9], the Netherlands [10,11],
Germany, and Britain [12]. Nowadays, OSDs have become one of the standard structures for steel bridge decks worldwide. However, with increasing service time, OSDs have been found to have many fatigue cracks, as shown in Figure 1 [13]. Studies [14, 15] found that one of the key reasons for cracking was the insufficiency of local stiffness of OSDs. Figure 2 shows that under axle loading of trucks, large local deformation would appear on the loading area, which tears the asphalt pavement and reduces the fatigue life of the OSD [13].

To reduce the occurrence of fatigue cracks, researchers started to discuss solutions in 1998. A group of Dutch officers, civil engineers, and scholars launched a study on the repair and prevention methods of OSD fatigue cracking. In 1999, they proposed laying ultrathin heavy reinforced highperformance concrete (UTHRHPC) on top of an OSD to solve the cracking problem [16]. Later, UTHRHPC was first paved on the OSD of the Van Brienenoord Bridge in the Netherlands with a paving area of $60 \mathrm{~m}^{2}$ [17]. According to 


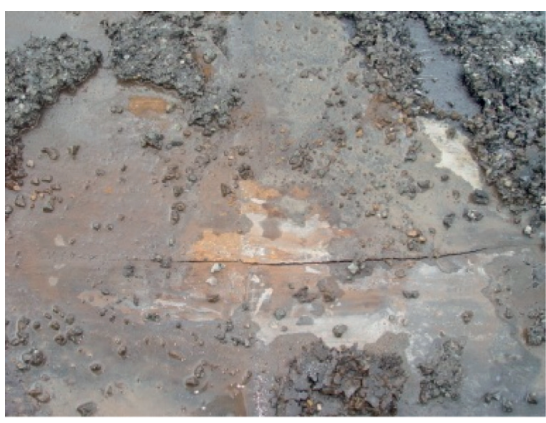

(a)

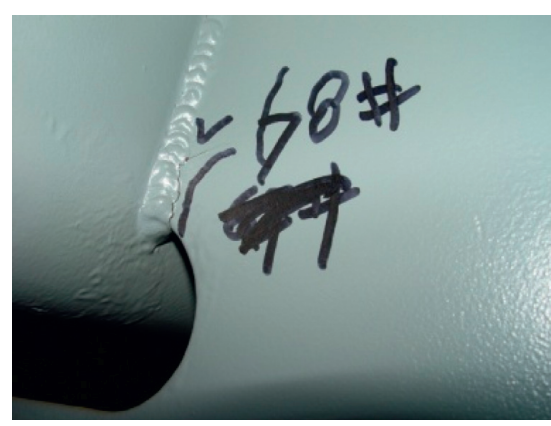

(b)

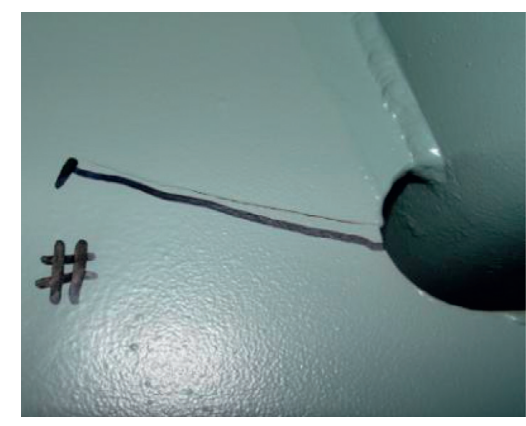

(c)

FIgURE 1: Cracks in OSDs: (a) crack in top plate; (b) crack in rib-diaphragm joint; (c) crack in diaphragm [13].

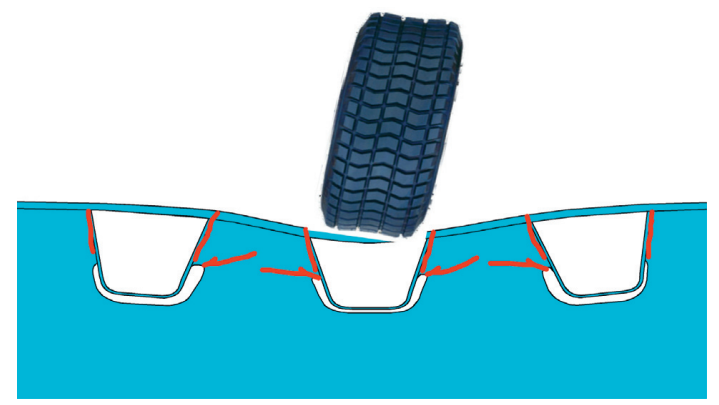

FIGURE 2: Illustration of OSD deformation under truck load [13].

the field test results, the $50 \mathrm{~mm}$ thick UTHRHPC significantly reduced the fatigue stress of the OSD of Van Brienenoord Bridge from $124 \mathrm{MPa}$ to $23 \mathrm{MPa}$. Since then, researches and implementations of the hard overlay on OSD have surged. In 2001, asphalt pavement on the Rio-Niteroi Bridge in Brazil was replaced by reinforced concrete slabs (RCSs) to solve the cracking problem of OSDs $[18,19]$. In 2002, De Jong and Kolstein suggested using a two-component epoxy layer with bauxite to connect OSD and a reinforced high-performance concrete (RHPC) layer. Then, this technique was applied in the Caland Bridge in 2003. The field test results showed that the stress of the Caland Bridge deck and the rib deck weld was reduced by $80 \%$ and $60 \%$, respectively [20]. In 2004, De Jong proposed various OSD strengthening methods using different materials and structures in his doctoral dissertation [11]. In 2005, asphalt pavement on the Shonan Ohashi Bridge in Japan was replaced with a $70 \mathrm{~mm}$ thick steel fiber-reinforced concrete (SFRC) layer. In addition, carbon fiber-reinforced plastic (CFRP) nets were used to strengthen the SFRC layer [9]. In 2011, asphalt pavement on the Illzach Bridge in France was replaced by prefabricated ultrahigh-performance fiberreinforced concrete (UHPFC) slabs [21]. The UHPFC slabs were prefabricated in a factory and installed in place. Shear studs and UHPFC were used to connect the slabs and OSD. The replacement significantly reduced the stress of the deck plate and U-rib by $50 \%$ and $30 \%$, respectively. In 2013, De Freitas et al. proposed using steel plates to strengthen the OSD, as shown in Figure 3 [22]. In 2020, Chen et al. proposed a crack-fixing method which was retrofitting the cutout of the cracked diaphragm and strengthening the diaphragm by reinforced steel plates [1].

Behind those prevention methods of OSD cracking, there were a large number of experimental studies, including shear test, static loading test, and fatigue test. Zhu et al. studied the shear behavior of steel-UHPC composite beams in waffle bridge deck [23]. Test results showed that shear spans would change the failure mode of steel-UHPC composite beams. And the height of the rib in the waffle slab acted less importantly than the thickness of slab on improving the shear resistance of composite beam. Wang et al. conducted push-out tests of demountable headed stud shear connectors in steel-UHPC composite structures [24]. Test results showed that demountable headed stud shear connectors were strong enough to be used in practice, and it was recyclable and environment-friendly. Zhang et al. studied the static and fatigue behavior of rubber-sleeved stud shear connectors [25]. Results showed that the rubber-sleeved stud shear connector has sufficient deformation capacity and its slip capacity was 1.5 times that of the ordinary stud shear connector. Zhao et al. studied the shear performance of short U-shape connectors in a steel-UHPC composite deck [26]. Results showed that the short U-shape connectors had higher stiffness than the conventional connectors. The height of U-shape steel impacted the strength of the connectors seriously. Chen et al. conducted a fatigue test of UHPC-orthotropic composite deck [27]. Test results showed that UHPC could effectively improve the shear fatigue life of composite beams, and the shear fatigue life of UHPCorthotropic composite beams was much greater than the design requirement.

To date, various OSD strengthening methods have been proposed. However, the previous design viewed the hard overlays as affiliated components that were only used to improve the local stiffness of the OSD. In this paper, an innovative steel-UHPC lightweight composite deck (LWCD) used in a self-anchored suspension bridge (Fengxi Bridge) in China is introduced. LWCD takes the UHPC layer as a part of the top plate. Such design not only increases the deck's local stiffness but also reduces the thickness of the steel top plate of the OSD. Therefore, LWCD can not only significantly reduce the fatigue stress of the deck but also reduce the steel consumption of the deck. Moreover, since 


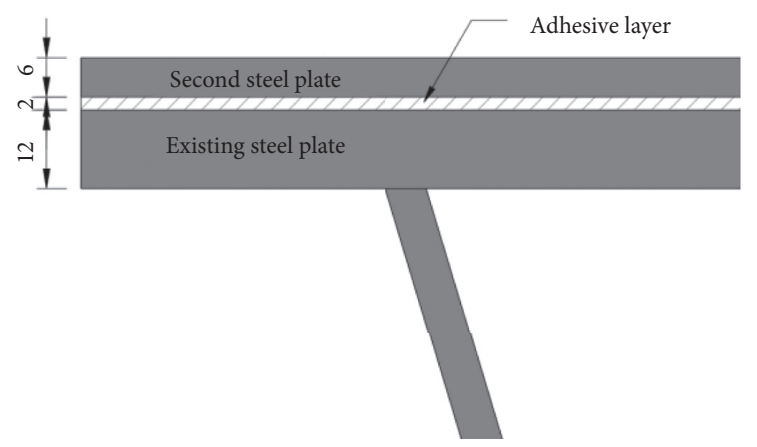

(a)

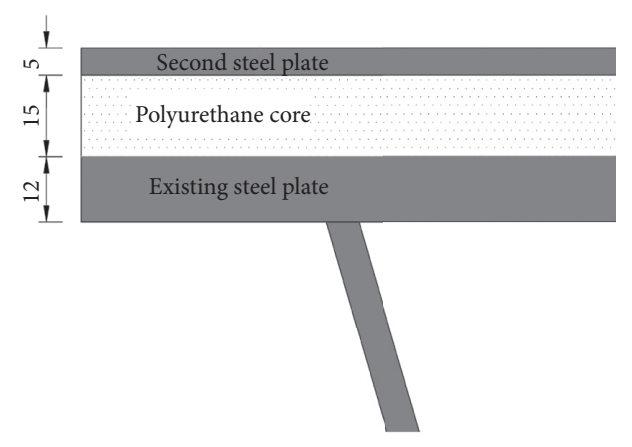

(b)

FIgURE 3: OSD strengthening methods (unit: $\mathrm{mm}$ ): (a) bonded steel plate; (b) sandwich steel plates [22].

UHPC construction joint strengthening methods and repair techniques are rarely seen in literature, this paper introduces two innovative UHPC construction joint strengthening methods and a UHPC bridge deck repair method. In addition, numerical simulations and laboratory tests, which were carried out to validate the design of LWCD, are introduced. Finally, the construction technique and economic benefits of LWCD are discussed.

\section{Engineering Background}

The Fengxi Bridge is a self-anchored suspension bridge located in Zhuzhou City, Hunan Province, southern China. It provides six lanes and two sidewalks in two directions. It is an important urban transportation link connecting Tianyuan District and Lusong District in Zhuzhou City, as shown in Figure 4. The Fengxi Bridge has a total length of $570 \mathrm{~m}$ and a main span of $300 \mathrm{~m}$. The span configuration is $3 \times 45 \mathrm{~m}+300 \mathrm{~m}+3 \times 45 \mathrm{~m}$. The side span parts of the main girder include concrete box girder while the main span part is UHPC-steel lightweight composite girder, as shown in Figure 5. Both of the towers are made from concrete and shaped like portals. The one on the north bank is $97.4 \mathrm{~m}$ high, and the one on the south bank is $102.4 \mathrm{~m}$ high, as shown in Figure 6. The main girder of the Fengxi Bridge is $3.5 \mathrm{~m}$ high and $32 \mathrm{~m}$ wide, as shown in Figure 7. The main cables were made of 33 bundles of 91p5.1 galvanizing-5\% aluminum-rare earth alloy high-strength parallel steel wire. Each main cable's diameter is $312.5 \mathrm{~mm}$ with a void ratio of $20 \%$, as shown in Figure 8 . The distance between the centers of the two cables is $22.5 \mathrm{~m}$, and the rise-span ratio of the cables is $1 / 5$. The construction of the Fengxi Bridge started on December 26, 2011, and was completed in 2016. The total project investment was 790 million RMB $(\approx 118$ million USD).

\section{Design of LWCD}

The Fengxi Bridge is the first bridge to use LWCD as a bridge deck system. Figures 9 and 10 show the details of the LWCD used in the Fengxi Bridge. The top plate of the LWCD consisted of stone mastic asphalt (SMA) layer, UHPC layer, shear studs, rebar net, and steel plate. The thicknesses of the UHPC layer and SMA layer were both $50 \mathrm{~mm}$. The rebar net was made of $\Phi 10$ HRB 400 rebar with transverse and longitudinal distances of $50 \mathrm{~mm}$. It was used to reinforce the UHPC layer. Shear studs

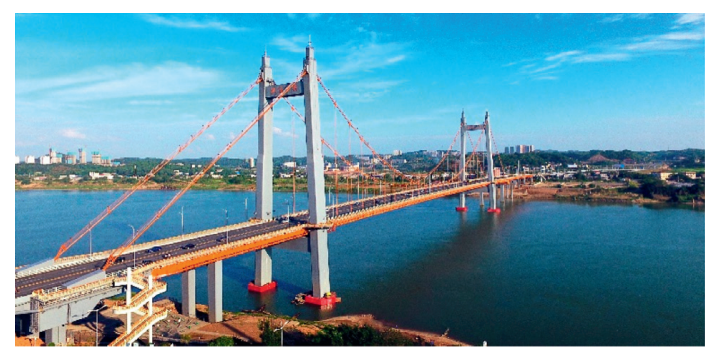

FIgURE 4: Aerial view of the Fengxi bridge.

with a height of $40 \mathrm{~mm}$ and a diameter of $13 \mathrm{~mm}$ were welded on the steel plate by drawn-arc welding. The transverse and longitudinal distances between studs were $150 \mathrm{~mm}$. Trapezoidal ribs with a thickness of $8 \mathrm{~mm}$ were welded to the bottom of the top plate with a transverse distance of $600 \mathrm{~mm}$. Steel diaphragms with a thickness of $12 \mathrm{~mm}$ were welded to the top plate and the ribs with a longitudinal distance of $3000 \mathrm{~mm}$.

There are two main innovations in LWCD. The first is that the UHPC layer of LWCD is made of a specific type of reactive powder concrete with high strength and long durability [29]. The mechanical parameters of the UHPC of the LWCD are listed in Table 1. The second innovation is that LWCD combines OSD and UHPC to create a new type of steelconcrete composite structure [28]. Such a composite structure inherits the advantages of the traditional steel-concrete composite structure but has much lighter weight. In LWCD, the UHPC layer not only enhances the local stiffness of the OSD but also enhances the longitudinal strength of the girder. Therefore, the thickness of the top steel plate of the OSD can be reduced. In the Fengxi Bridge, by adopting LWCD, the top steel plate of the OSD was reduced from $16 \mathrm{~mm}$ to $14 \mathrm{~mm}$, which saved a total of 202 tons of steel. Therefore, compared with conventional OSDs, LWCDs have the advantages of higher stiffness, lighter weight, and lower manufacturing cost.

\section{Numerical and Experimental Analysis of LWCD}

To validate the effectiveness and superiority of LWCD, a numerical simulation, a static loading test, and a fatigue test were carried out in this research. This section introduces the tests and results. 




FIgure 5: Elevation of the Fengxi bridge (unit: $\mathrm{m}$ ).

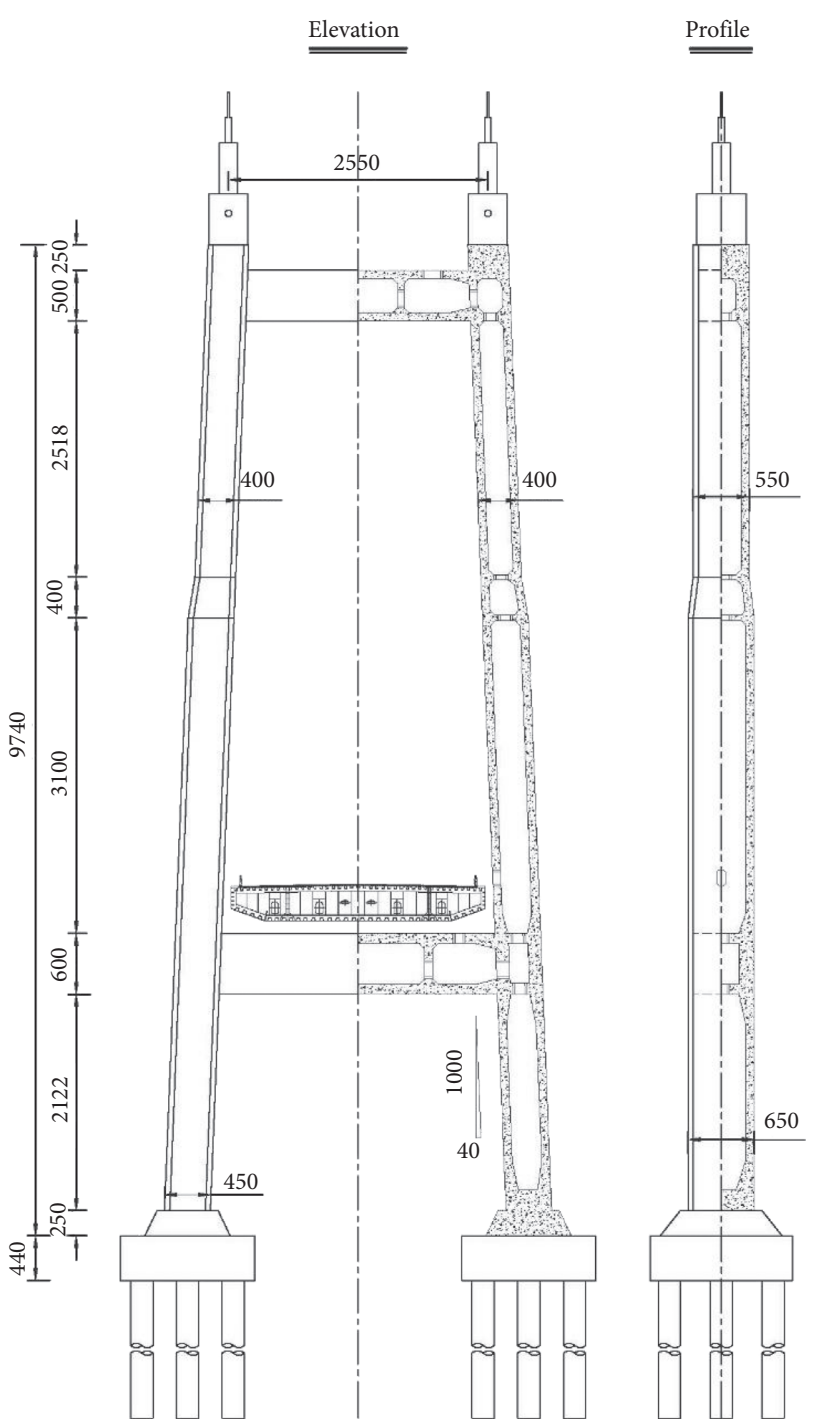

FIGURE 6: Elevation of the pylon (unit: $\mathrm{cm}$ ).

4.1. Numerical Simulation. In this research, a finite element model (FEM) of the LWCD and a FEM of the conventional OSD were established, respectively, as shown in Figure 11. Models were established to study the effect of LWCD on stress reduction. Both models were 12 meters long, which is



FIgURe 7: Cross section of the main girder (unit: $\mathrm{cm}$ ).

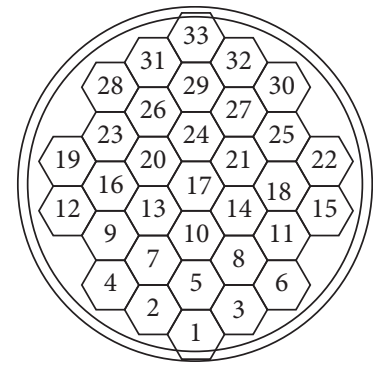

Figure 8: Cross section of the main cable.

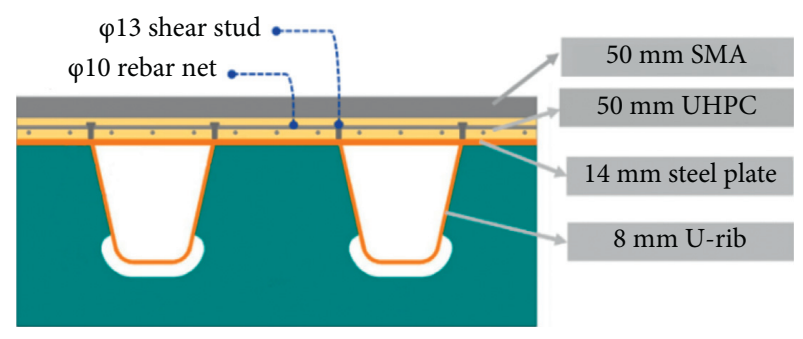

Figure 9: Details of LWCD [13].

equal to the interval length between cable hangers of Fengxi Bridge. The width of the models was 16 meters, and the height was 3.5 meters, which is equal to the real dimensions of Fengxi Bridge. The top plate thicknesses of the conventional OSD model and LWCD model were $16 \mathrm{~mm}$ and $12 \mathrm{~mm}$, respectively. Both top plates were strengthened by U-ribs with a height of $280 \mathrm{~mm}$ and a spacing of $600 \mathrm{~mm}$. A 


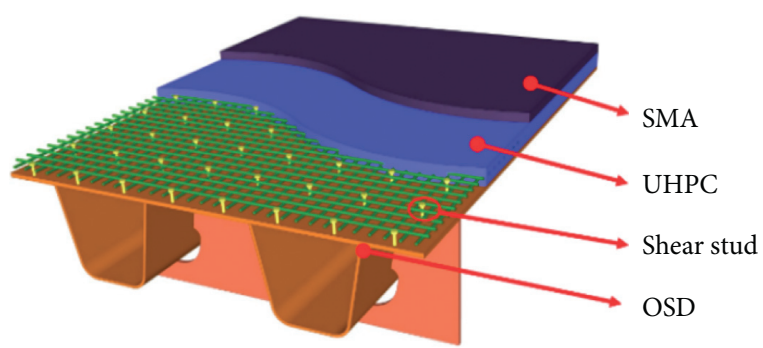

Figure 10: 3D plot of LWCD [28].

TABLE 1: Mechanical parameters of the UHPC of Fengxi Bridge.

\begin{tabular}{|c|c|}
\hline Properties & Values \\
\hline Compressive strength & $\geq 110$ \\
\hline Tensile strength & $\begin{array}{c}\geq 8 \mathrm{MPa} \text { (without rebar) } / \geq 40 \mathrm{MPa} \text { (with } \\
\text { rebars) }\end{array}$ \\
\hline Shea & \\
\hline Shr & $\begin{array}{c}\leq 600 \mu \varepsilon \text { (regular curing) } / \leq 100 \mu \varepsilon(\text { steam } \\
\text { curing) }\end{array}$ \\
\hline & $\leq 2.0$ (regular curin \\
\hline $200 \mathrm{~N}$ & $\begin{array}{l}\geq 50 \mathrm{MPa} \text { (compressive stress amplitude)/ } \\
\geq 20 \mathrm{MPa} \text { (tensile stress amplitude) }\end{array}$ \\
\hline
\end{tabular}

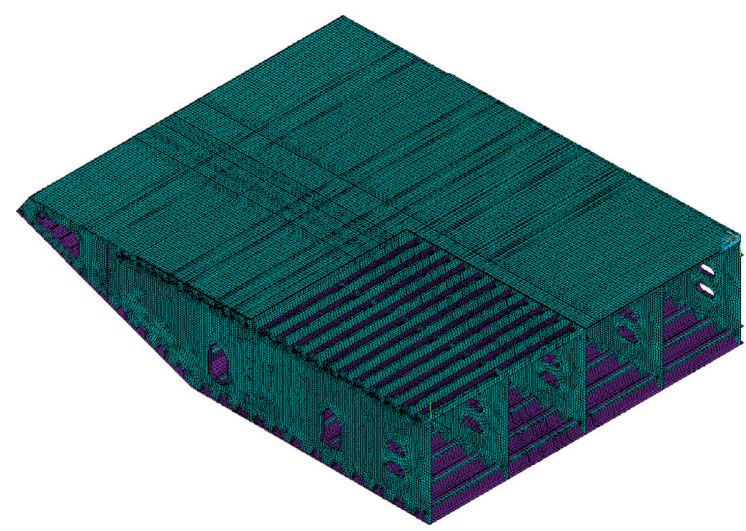

Figure 11: The FEM of LWCD.

UHPC layer with a thickness of $50 \mathrm{~mm}$ was applied on the top of the LWCD model. For element types, all steel parts were simulated by SHELL 63 elements with an elastic modulus of $2.06 \times 10^{5} \mathrm{MPa}$ and a Poisson's ratio of 0.3 . UHPC parts were simulated by SHELL 181 elements with an elastic modulus of $4.26 \times 10^{4} \mathrm{MPa}$ and a Poisson's ratio of 0.2 .

For load settings, according to the Chinese Highway Bridge Design Code [30], the standard dead loads and live loads are listed in Table 2. Both the dead loads and live loads were applied to both models at the same time. To compare the stress level between the LWCD and OSD models, five stress observation points where cracks were commonly seen in OSD were selected, as shown in Figure 12.

Simulation results are shown in Figure 13 and Table 3. It could be seen that the tensile stress of OP- 1 to OP-5 of the LWCD was less than that of the conventional OSD by $84.6 \%$,
$51.5 \%, 34.3 \%, 89.4 \%$, and $19.3 \%$, respectively. The compressive stress of OP- 1 to OP- 5 of the LWCD was less than that of the OSD by $89.7 \%, 40.6 \%, 43.9 \%, 75.4 \%$, and $31.9 \%$, respectively. Therefore, the numerical analysis showed that under the design loads, the stress level on the LWCD is much less than that of the conventional OSD.

4.2. Static Loading Test of LWCD. A static loading test was conducted to verify the conclusion drawn from the numerical simulation. In the test, a full-scale OSD segment and a full-scale LWCD segment were made and tested. The details of the segments and loading position are shown in Figures 14 and 15. The size of the two segments was $5.2 \mathrm{~m}$ long, $4.2 \mathrm{~m}$ wide, and $1.06 \mathrm{~m}$ high. To simulate the wheel load of heavy vehicle, the size of the loading area was set to the size of the contact area between wheel and road surface. The length and width of the loading area were $0.2 \mathrm{~m}$ and $0.6 \mathrm{~m}$, respectively [30]. The magnitude of the static load was set to $100 \mathrm{kN}$ [30], and the load was applied vertically on the segments by a hydraulic jack. A force gage was installed on the tip of the hydraulic jack to measure the real-time loading force. To avoid any dynamic impact, the load was applied very slowly. The whole loading process consumed about 20 minutes. To measure the critical stress in the specimen, six stress observation points on the segments were selected, as shown in Figure 16. Strain gages were used to capture the strain and stress. Test results are listed in Table 4.

Table 4 shows that in LWCD, the stress of the rib-to-deck welded connection was reduced by $66 \%$ to $90 \%$. The stress of the rib-to-diaphragm welded connection was reduced by $31 \%$ to $65 \%$. The stress of the rib bottom was reduced by $51 \%$. Thus, the static loading test was consistent with the simulation results. They solidly proved that the stress level on the LWCD was much less than that of the conventional OSD. The reason for the reduction is that the UHPC layer significantly increases the local stiffness of the LWCD. Thus, under the same load, the local deformation of LWCD is much smaller than the local deformation of the conventional OSD. Less local deformation causes less stress concentration. Point 1 to Point 6 are points where stress concentration commonly happens. Therefore, adopting LWCD would greatly reduce the stress of Point 1 to Point 6 and even the whole structure.

4.3. Fatigue Test of LWCD. To test the fatigue life of LWCD, a fatigue test was conducted on the full-scale LWCD segment with $50 \mathrm{~mm}$ UHPC layer. According to FEM analysis, under the $550 \mathrm{kN}$ standard vehicle load of the Chinese Highway Bridge Design Code [30], the stress of the cutout edge near the load (as shown in areas \#3 and \#5 in Figure 17) was approximately $68.2 \mathrm{MPa}$. Thus, to cause cyclical stress of 68.2 $\mathrm{MPa}$ in the cutout edge of the diaphragm near the vehicle load, a cyclical load generated by an actuator was placed on the segment, as shown in Figure 17. U-rib No. 3 and No. 5 in Figure 17 were selected as strain observation points. Strain gages were used to capture the strain and stress, as shown in Figure 18. 
TABLE 2: Loads applied on the FEM.

\begin{tabular}{lccccc}
\hline $\begin{array}{l}\text { Load } \\
\text { type }\end{array}$ & Dead load & $\begin{array}{c}\text { Vehicle } \\
\text { load }\end{array}$ & Pedestrian load & $\begin{array}{c}\text { Uniform temperature } \\
\text { load }\left({ }^{\circ} \mathrm{C}\right)\end{array}$ & Temperature difference load \\
\hline Values & $\begin{array}{c}0.72 \times 10^{-3} \mathrm{~N} / \\
\mathrm{mm}^{2}\end{array}$ & $\begin{array}{c}260 \mathrm{kN} / \\
\text { axle }\end{array}$ & $\begin{array}{c}5.0 \times 10^{-3} \mathrm{~N} / \\
\mathrm{mm}^{2}\end{array}$ & 25 & $\begin{array}{c}\text { Temperature difference between UHPC layer and } \\
\text { OSD is } 15^{\circ} \mathrm{C}\end{array}$ \\
\hline
\end{tabular}

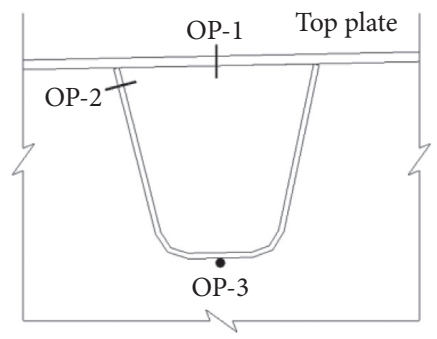

(a)

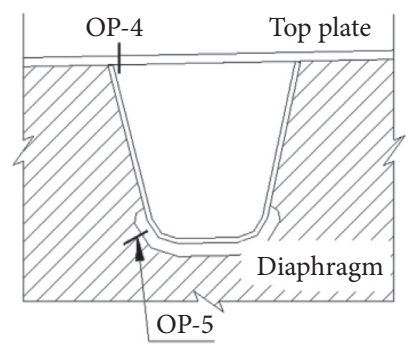

(b)

FiguRE 12: Stress observation points: (a) without diaphragm; (b) with diaphragm.

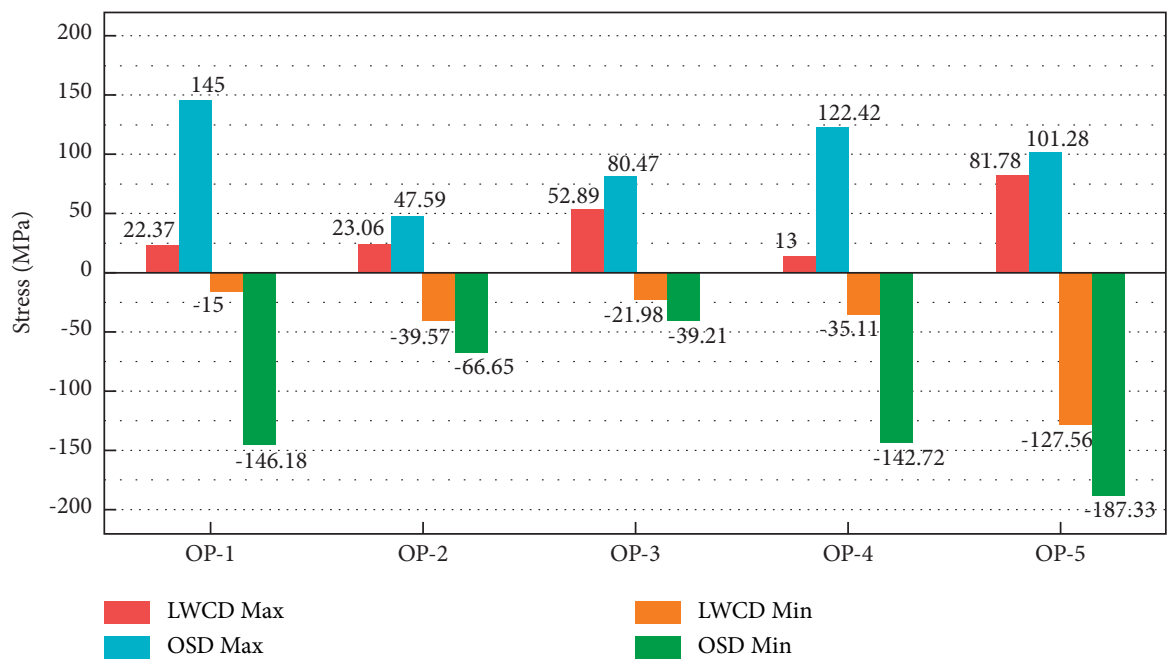

FIgURE 13: Bar chart of stress of OP-1 to OP-5 under traffic loads (sign: “+," tensile; “-," compressive).

TABLE 3: Stress at each observation point (sign: “+,” tensile; “-,” compressive).

\begin{tabular}{|c|c|c|c|c|c|c|}
\hline \multirow[t]{2}{*}{ Observation points } & \multicolumn{2}{|c|}{ LWCD (MPa) } & \multicolumn{2}{|c|}{ OSD (MPa) } & \multicolumn{2}{|c|}{$\begin{array}{c}\text { Stress reduction } \\
\text { percentage of LWCD } \\
\text { to OSD }\end{array}$} \\
\hline & Max & Min & Max & Min & Max & Min \\
\hline OP-1 & 22.37 & -15.0 & 145.0 & -146.18 & 84.6 & 89.7 \\
\hline OP-2 & 23.06 & -39.57 & 47.59 & -66.65 & 51.5 & 40.6 \\
\hline OP-3 & 52.89 & -21.98 & 80.47 & -39.21 & 34.3 & 43.9 \\
\hline OP-4 & 13.0 & -35.11 & 122.42 & -142.72 & 89.4 & 75.4 \\
\hline OP-5 & 81.78 & -127.56 & 101.28 & -187.33 & 19.3 & 31.9 \\
\hline
\end{tabular}

The test results showed that after 5.92 million cyclical loads, no cracks appeared in the whole LWCD model. The strain of the observation points increased by only $8.5 \%$, as shown in Figure 19. It was shown that the fatigue damage and stiffness attenuation of the LWCD were minor. Under the design loads, the fatigue life of the LWCD is at least 5 million times, which is much more than the design requirement of 2 million times. 


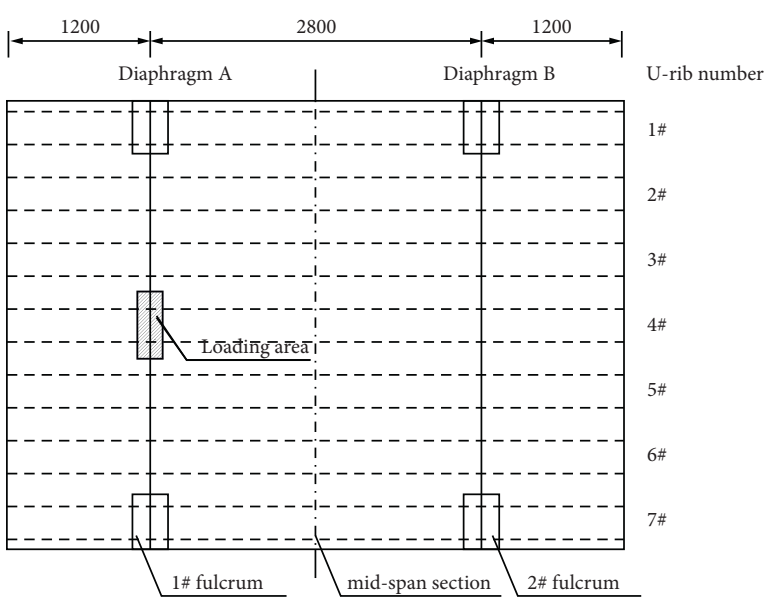

FIgURE 14: Top view of the test specimen.

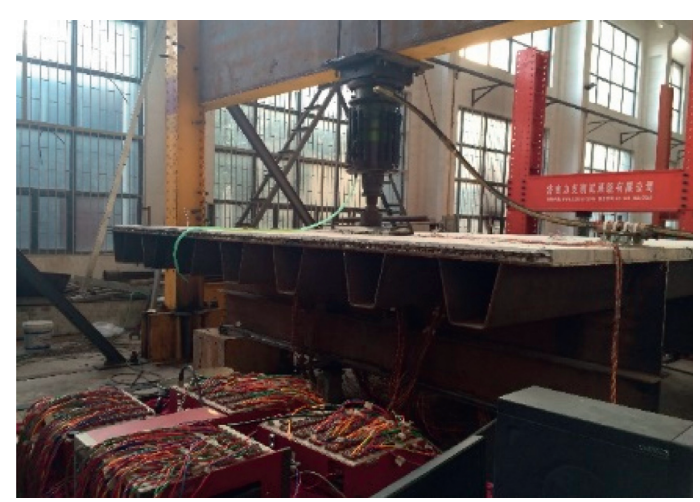

FIGURE 15: LWCD specimen and loading device.

\section{Design of Construction Joint of LWCD}

Construction joints are the weakest but crucial parts of UHPC bridge decks. The durability of construction joints determines the durability of UHPC bridge decks. However, according to the literature review [31], very few construction joint strengthening methods have been proposed. Thus, in this research, two kinds of construction joint strengthening techniques are proposed. The first is to increase the rebar of the joints and set the joints at the midpoint between diaphragms, as shown in Figure 20. This method places $150 \mathrm{~mm}$ short rebars between the regular rebars. The rebars of the left and right UHPC sections overlapped by $50 \mathrm{~mm}$ and were welded together. The second strengthening method is to weld an S-shaped steel plate on the deck along the joints and set the joints at the midpoint between diaphragms. Half of the S-shaped steel plate is embedded in the first-cast UHPC section, and the other half of the S-shaped steel plate is embedded in the construction joint, as shown in Figure 21. The reason to set the joints at the midpoint between diaphragms is that the smallest stress area of the deck under design loads is the middle area between diaphragms, as shown in Figure 22.

Two model tests were carried out to test the effectiveness of the strengthening methods, as shown in Figures 23 and 24. For the first strengthening method, the test results showed that when the short rebar diameter was $12 \mathrm{~mm}$, the joint's tensile strength could reach $21.8 \mathrm{MPa}$, as shown in Table 5 . For the S-shaped plate method, the test results showed that S-shaped steel plates could make the joint's tensile strength reach 17.9 $\mathrm{MPa}$. According to FEM simulation, under design loads, the tensile stress at the midpoint between diaphragms is approximately $8.65 \mathrm{MPa}$. Therefore, adopting either of the strengthening methods and placing the joints in between diaphragms can ensure the joints' safety, and the safety factors reach 2.07 to 2.52 .

\section{Construction and Repair Techniques of the UHPC Layer of LWCD}

6.1. UHPC Layer Construction Techniques and Procedure. According to the shrinkage properties of UHPC [32], the construction techniques of the UHPC layer of LWCD used in the Fengxi Bridge were as follows (see Figure 25).

Step 1: erect the OSD parts as conventional OSD girders.

Step 2: remove the rust on the top of the OSD parts and weld the shear studs on the OSD.

Step 3: paint antirust coating on the edge area of the deck. Since the UHPC layer is highly dense and almost waterproof, only the area within $0.5 \mathrm{~m}$ around the edge of UHPC layer is needed to be painted with antirust paint. The thickness of the antirust paint should be more than $80 \mu \mathrm{m}$.

Step 4: place rebar net on the top of the deck.

Step 5: cast UHPC. Note that since UHPC used in LWCD has high rapid coagulation characteristics, the fluidity of UHPC drops sharply after 20 to 30 minutes. Therefore, the UHPC mixing station should be built within $3 \mathrm{~km}$ of the construction site, and the UHPC transported to the site should be cast immediately.

Step 6: UHPC vibration and leveling. In this step, highfrequency vibration is needed to make the UHPC distribute evenly. To avoid concrete segregation, the plug-in vibrator should not be used.

Step 7: curing. In this step, the UHPC should be naturally cured for 48 hours with moisturizing films. After 48 hours, steam curing begins. Steam curing should keep a constant temperature above $80^{\circ} \mathrm{C}$ for more than 72 hours. The increased rate of the temperature should not exceed $12^{\circ} \mathrm{C} / \mathrm{h}$ until the temperature rises to $80^{\circ} \mathrm{C}$. The cooling rate should not exceed $15^{\circ} \mathrm{C} / \mathrm{h}$ until the temperature drops to the environmental temperature.

Step 8: UHPC surface roughening. In this step, the upper surface of the UHPC must be roughened to ensure sufficient adhesion between the UHPC layer and asphalt pavement before asphalt paving. After roughening, asphalt should be paved immediately to prevent the upper surface of the UHPC from being contaminated and rusted.

Step 9: asphalt layer paving. 


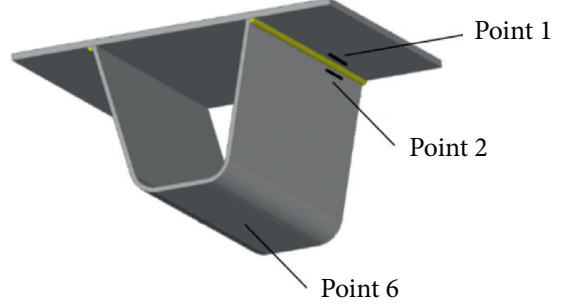

(a)

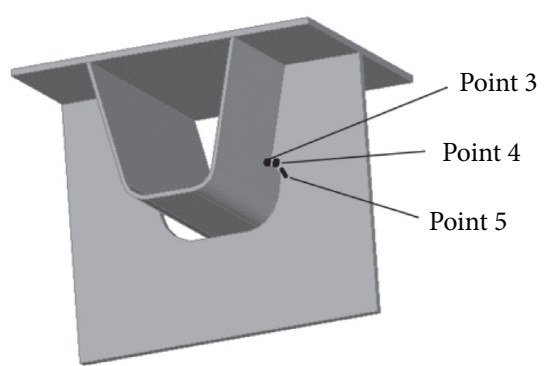

(b)

Figure 16: Locations of the six stress observation points.

TABle 4: The highest stress at different observation points (unit: MPa; sign: “-," compressive; “+,” tensile).

\begin{tabular}{lccc}
\hline Observation points & OSD $(\mathrm{MPa})$ & LWCD $(\mathrm{MPa})$ & Stress reduction percentage of LWCD to OSD \\
\hline Point 1 & -167 & -17 & 90 \\
Point 2 & +58 & +20 & 66 \\
Point 3 & +43 & +15 & 65 \\
Points 4 \& 5 & +39 & +27 & 31 \\
Point 6 & +76 & +37 & 51 \\
\hline
\end{tabular}

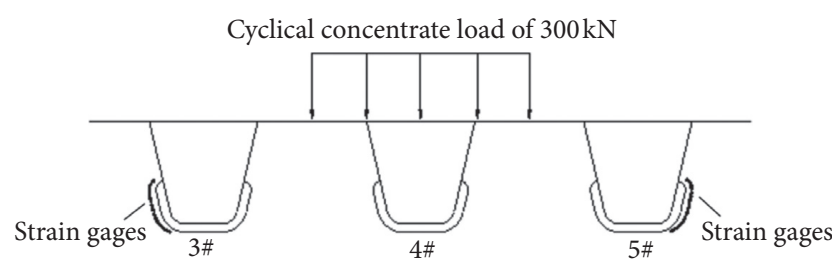

Figure 17: Loading and measuring positions of the test.

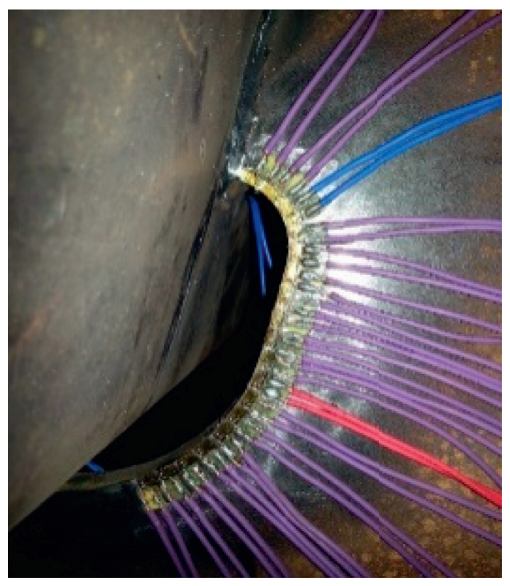

Figure 18: Strain gages on U-rib No. 5.

Due to the use of the above construction method, no bridge deck failure has been found in the Fengxi Bridge since it was opened to traffic in 2016.

6.2. UHPC Layer Repair Method. The design life of LWCD is 100 years. Thus, in the whole life cycle, the UHPC layer of LWCD inevitably encounters accidental damage. In this

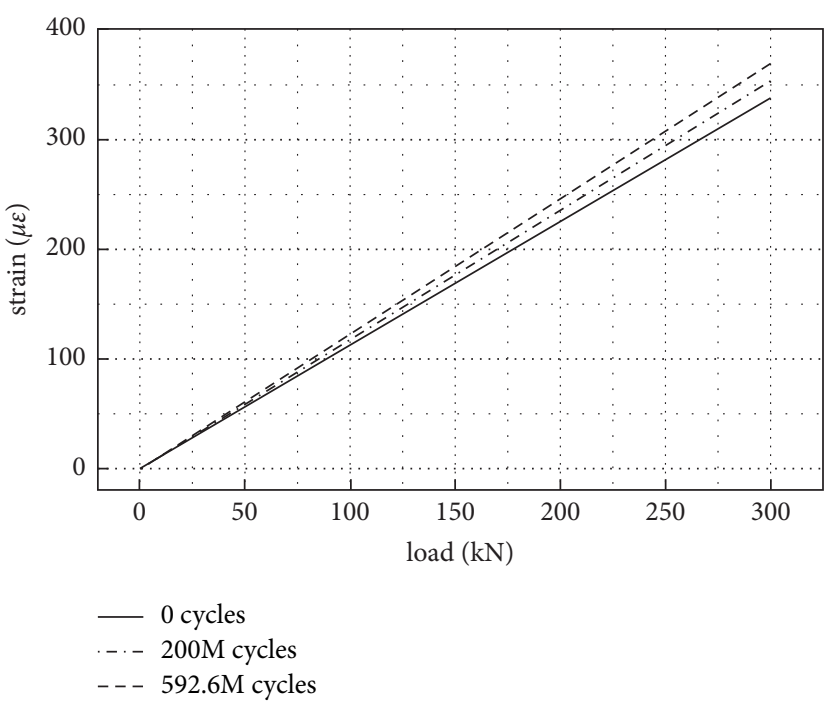

FIgURE 19: Load-strain curve at the measuring points.

research, a rapid repair method of the UHPC layer of LWCD was proposed, as shown in Figures 26 and 27. The repair procedure is as follows. First, a cutting machine is used to disconnect the damaged and undamaged areas, as shown in Figure 26(a). Then, the UHPC in the damaged area is cleaned with a pneumatic pick. Later, the damaged shear studs are checked and replaced (Figure 26(b)). Then, the UHPC along the edges with a width of ten times the rebar diameter is removed to expose the rebar embedded in the undamaged area (Figure 26(c)). Then, the old rebar and the new rebar are welded together (Figure 26(d)). In addition, a short rebar with a length of $10 \mathrm{~cm}$ and a diameter of $16 \mathrm{~mm}$ should be welded to each joint of the old and new rebar to improve the joint's strength. The post-reinforcement of the damaged area 


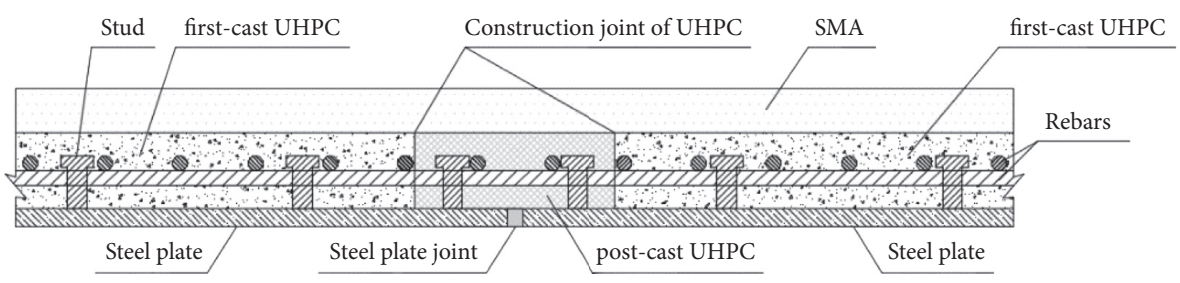

(a)



(b)

FIgURE 20: Design of the construction joint of the UHPC layer: (a) cross section; (b) top view.

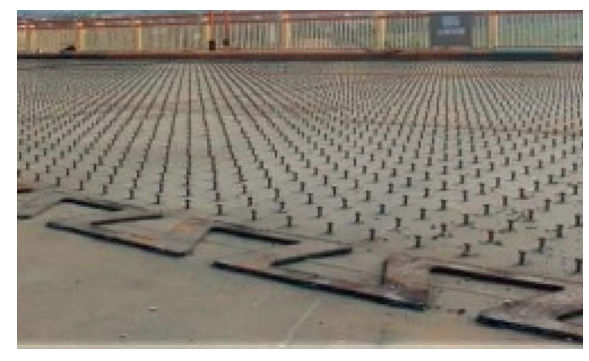

(a)

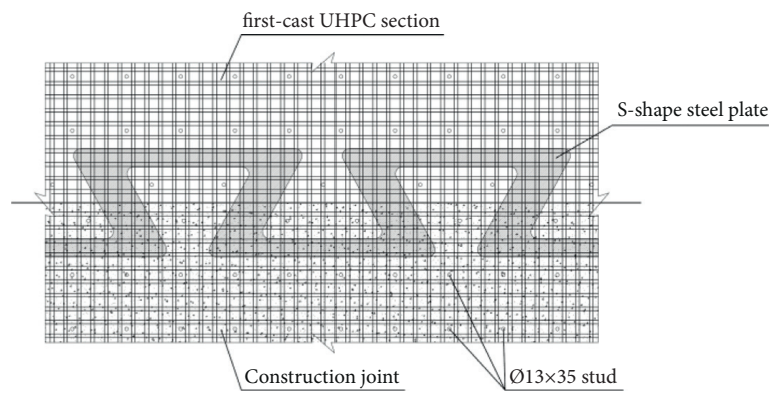

(b)

FiguRE 21: S-shaped plate reinforcement: (a) on-site; (b) schematic diagram.

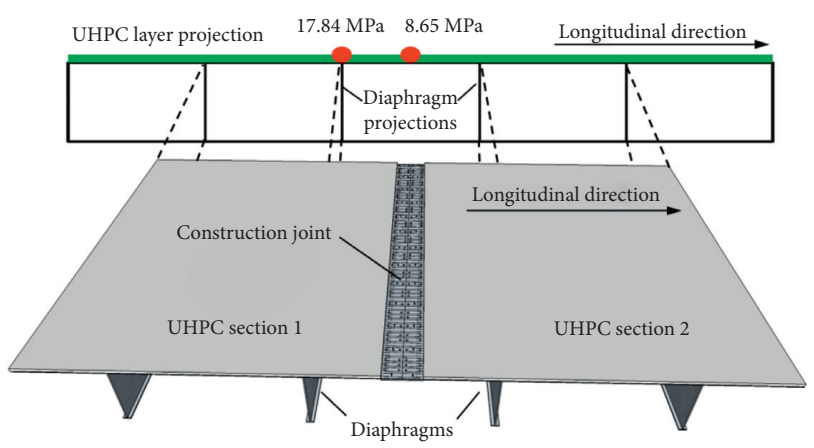

FIGURE 22: Stress distribution on deck and the position of the construction joint.

is shown in Figure 26(e). Finally, UHPC is cast onto the damaged area and cured (Figure 26(f)). Through a static loading test, the tensile strength of the repaired area was found to be $25.14 \mathrm{MPa}$, which was greater than the bridge deck tensile stress under design loads (17.84 MPa). Therefore, the repair method proposed in this research is applicable.

\section{Economic Benefits of LWCD}

Compared with conventional OSDs, LWCDs not only have better mechanical properties but also have better economic benefits. This section takes the Fengxi Bridge as an example. Table 6 shows the cost estimate of the Fengxi Bridge using different deck systems. In the manufacturing stage, the cost difference mainly comes from the steel consumption and the amount of UHPC. LWCD saves 202 tons of steel but uses $6750 \mathrm{~m}^{2}$ UHPC more than the conventional OSD. In sum, the manufacturing cost (MC) of LWCD is $32,500 \mathrm{k}$ RMB $(\approx 4850 \mathrm{k}$ USD), while the MC of conventional OSD is $33,430 \mathrm{k}$ RMB $(\approx 4990 \mathrm{k}$ USD). Therefore, in the manufacturing stage, adopting LWCD could save 940k RMB $(\approx 140 \mathrm{k}$ USD) more than adopting the conventional OSD. For the whole life cycle, the cost difference mainly comes 


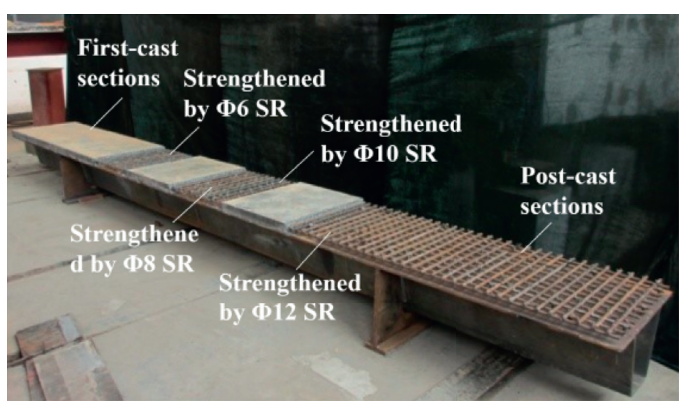

(a)

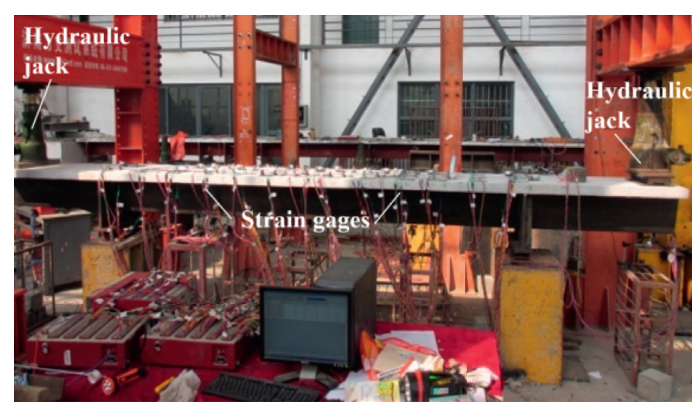

(b)

FIGURE 23: Static loading experiment for testing the tensile strength of joints with different local strengthening rebar diameters: (a) model; (b) experimental setup.

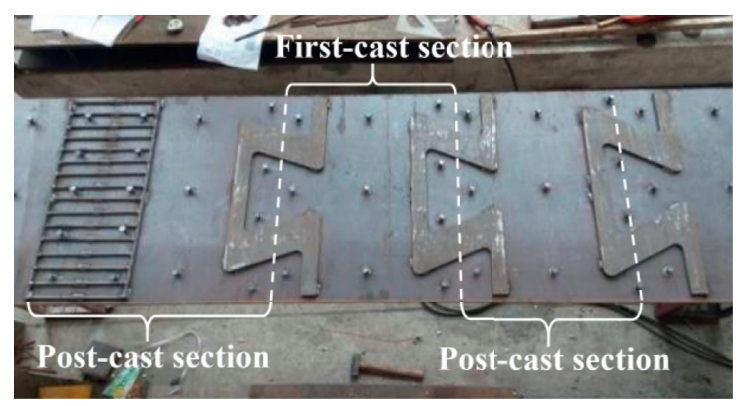

(a)

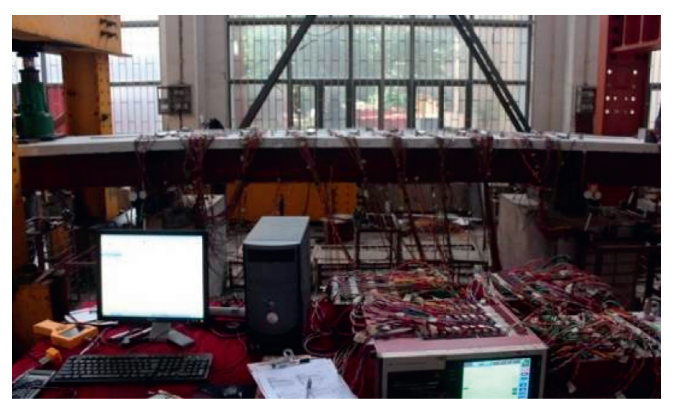

(b)

Figure 24: Static loading experiment for testing the effectiveness of the S-shaped steel plate: (a) model; (b) experimental setup.

TABle 5: Tensile strength of the joints with different sizes of rebar.

\begin{tabular}{lccrr}
\hline Diameter of the short rebar $(\mathrm{mm})$ & $\Phi 6$ & $\Phi 8$ & $\Phi 10$ & $\Phi 12$ \\
\hline Tensile strength of the joints $(\mathrm{MPa})$ & 13.2 & 16.6 & 19.4 & 21.8 \\
\hline
\end{tabular}

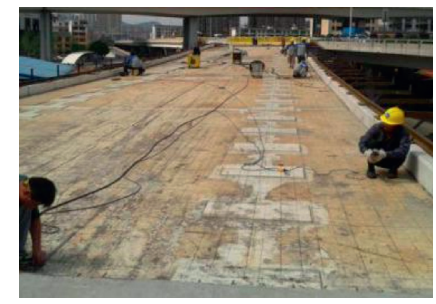

(a)

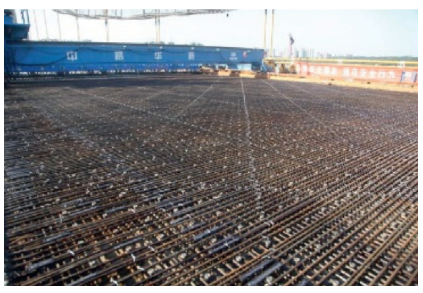

(d)

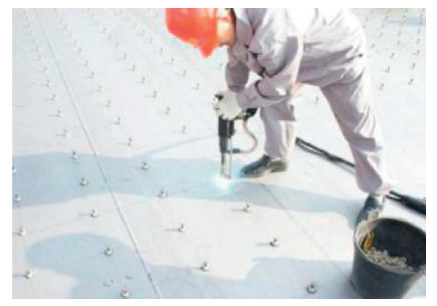

(b)

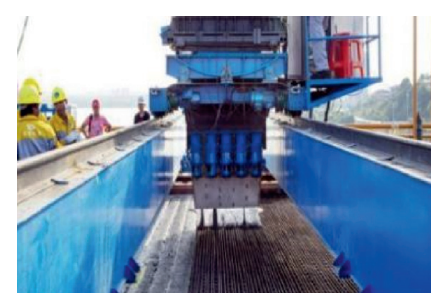

(e)



(c)

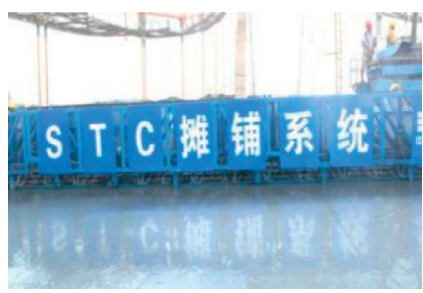

(f)

Figure 25: Continued. 


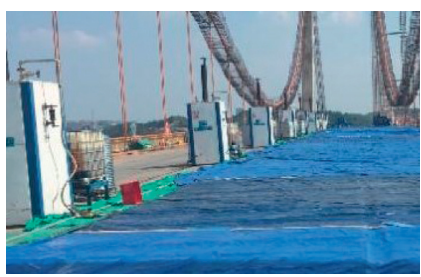

$(\mathrm{g})$



(h)

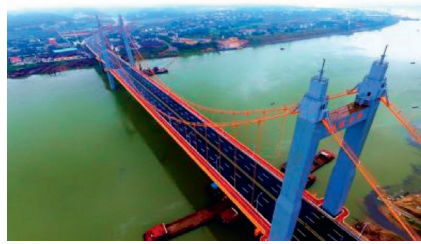

(i)

FIGURE 25: Construction procedure of LWCD: (a) bridge deck cleaning and rust removal; (b) shear stud welding; (c) antirust coating; (d) placing rebar net; (e) UHPC casting; (f) UHPC vibration and leveling; (g) steam curing; (h) UHPC surface roughening; (i) asphalt layer paving.

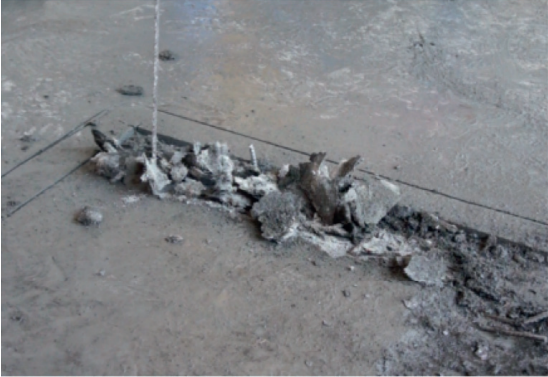

(a)

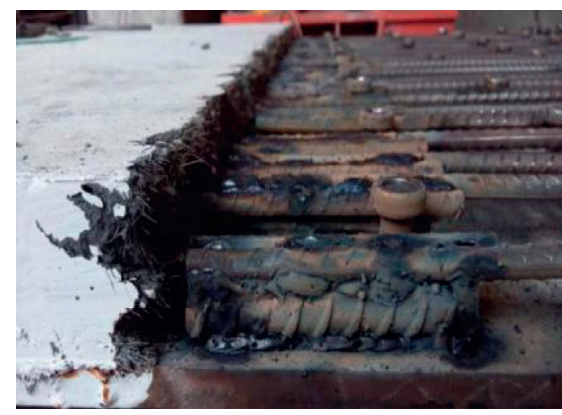

(d)

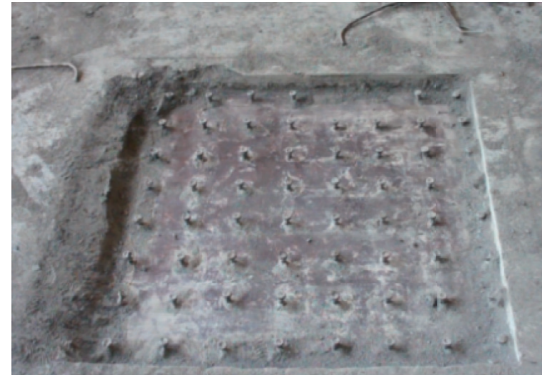

(b)

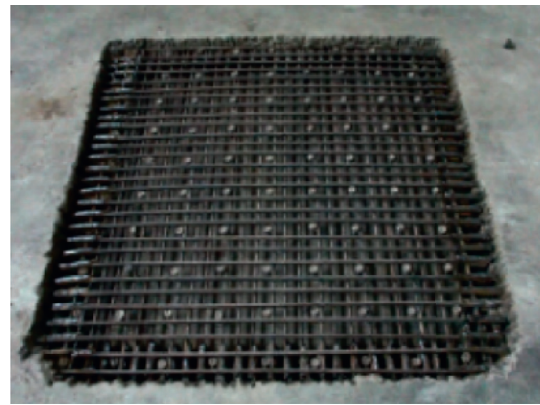

(e)

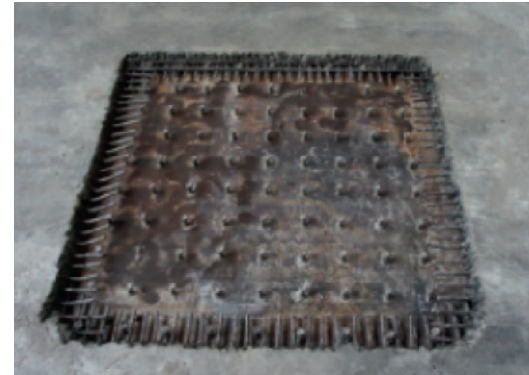

(c)

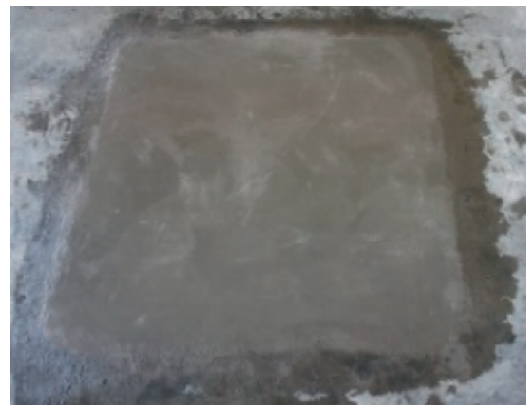

(f)

FIGURE 26: LWCD repair procedure: (a) breaking the damaged UHPC; (b) cleaning the debris; (c) digging out the old rebars; (d) welding the old and new rebars together; (e) new reinforcement; (f) new UHPC.

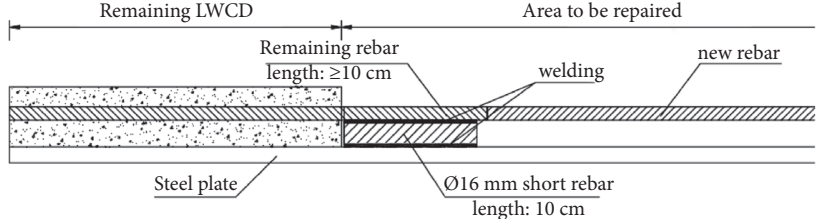

(a)

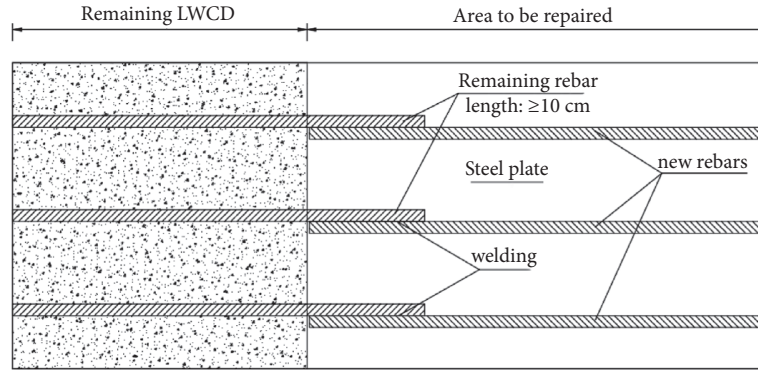

(b)

Figure 27: Repair joint design: (a) elevation view; (b) top view.

from the replacement of asphalt overlay because the conventional OSD uses EA as asphalt overlay, while LWCD uses SMA as asphalt overlay. As shown in Table 6, the unit price of SMA is much cheaper than the unit price of EA. According to estimates, the asphalt overlay of the Fengxi Bridge should be replaced 11 times in its whole life. In sum, 
TABLE 6: Comparison between the cost of LWCD and OSD for the Fengxi Bridge (unit: USD).

\begin{tabular}{|c|c|c|c|c|c|c|c|c|c|c|}
\hline \multirow{2}{*}{ Items } & \multirow{2}{*}{ Unit } & \multirow{2}{*}{ Unit price } & \multicolumn{4}{|c|}{ LWCD } & \multicolumn{4}{|c|}{ Conventional OSD } \\
\hline & & & Amount & $\mathrm{MC}(\mathrm{k})$ & Replacement times (RT) & WLC (k) & Amount & MC (k) & RT & WLC $(\mathrm{k})$ \\
\hline Steel & $\mathrm{t}$ & 2090 & 1415 & 2957 & 0 & 2957 & 1617 & 3378 & 0 & 3378 \\
\hline UHPC & $\mathrm{m}^{2}$ & 269 & 6750 & 1816 & 0 & 1816 & 0 & 0 & 0 & 0 \\
\hline SMA & $\mathrm{m}^{2}$ & 12 & 6750 & 81 & 11 & 972 & 0 & 0 & 0 & 0 \\
\hline EA & $\mathrm{m}^{2}$ & 239 & 0 & 0 & 0 & 0 & 6750 & 1612 & 11 & 19343 \\
\hline Total cost & M & & & 4.9 & & 5.8 & & 5.0 & & 22.7 \\
\hline Cost difference & M & \multicolumn{9}{|c|}{ MC of LWCD is $140 \mathrm{k}$ USD less, and WLC of LWCD is 17 million USD less } \\
\hline
\end{tabular}

Note. MC is the manufacturing cost; WLC is the whole life cost.

adopting the LWCD in the Fengxi Bridge saves a total of 113 million $\mathrm{RMB}(\approx 17$ million USD) compared to adopting the conventional OSD. Thus, the economic benefits of LWCD are superior to the conventional OSD.

\section{Conclusions}

This paper introduced an innovative bridge deck system (LWCD) in detail, including its design, construction techniques, repair methods, and construction joint strengthening methods. In addition, laboratory tests, numerical simulations, and economic analyses were conducted to verify the benefits of LWCD. Based on the research and the application of the Fengxi Bridge, the following conclusions can be drawn:

(1) Under the same loads, the stress level of the LWCD is much less than that of the conventional OSD. By using LWCD, the stress of the rib-to-deck welded connection can be reduced by $66 \%$ to $90 \%$. The stress of the rib-to-diaphragm welded connection can be reduced by $31 \%$ to $65 \%$. The stress of the rib bottom can be reduced by $51 \%$.

(2) Under design loads, the fatigue life of LWCD is more than 5 million cycles, which is much higher than the design requirement of 2 million cycles. Therefore, adopting LWCD can effectively solve the fatigue cracking problem of conventional OSDs.

(3) The proposed construction joint strengthening methods can improve the joint tensile strength to 21.8 MPa. According to the FEM simulation, the smallest tensile stress on the bridge deck is $8.65 \mathrm{MPa}$, which is at the midpoints between diaphragms. Thus, adopting the proposed construction joint strengthening methods and placing the joints at the midpoints between diaphragms can ensure the safety of the construction joints.

(5) The proposed LWCD damage repair method can make the tensile strength of the repaired area reach 25.14 MPa, which is greater than the maximum tensile stress of the bridge deck under design loads. Therefore, the proposed LWCD repair method is applicable.

(6) LWCD is much more economical than conventional OSD. In the Fengxi Bridge, the adoption of LWCD saved 140k USD in the construction phase and will save 17 million USD in the whole life cycle.
Therefore, LWCD is better in durability and economy than conventional OSD. It is recommended to use LWCD instead of conventional OSD in steel bridges. Since its application in the Fengxi Bridge, LWCD has been used in several long-span bridges in China, such as Dongting Bridge, a suspension bridge with a span of $1480 \mathrm{~m}$, and Zhaohua Bridge, a self-anchored suspension bridge with a span of $228 \mathrm{~m}$.

\section{Data Availability}

The data supporting this study are from previously reported studies and datasets, which have been cited. The processed data are available in [13].

\section{Conflicts of Interest}

The authors declare that they have no conflicts of interest.

\section{Acknowledgments}

The authors would like to express their sincere thanks to Prof. Xudong Shao and his research group from Hunan University for their great support in this project. This research was supported by the Transportation Technology Project of Hunan Province (201437) and Natural Science Foundation of Shandong Province (ZR2018LE017).

\section{References}

[1] Z.-Y. Chen, C.-X. Li, J. He, and H.-H. Xin, "Retrofit fatigue cracked diaphragm cutouts using improved geometry in orthotropic steel decks," Applied Sciences, vol. 10, no. 11, Article ID 3983, 2020.

[2] Z. Zhu, Z. Xiang, and Y. E. Zhou, "Fatigue behavior of orthotropic steel bridge stiffened with ultra-high performance concrete layer," Journal of Constructional Steel Research, vol. 157, pp. 132-142, 2019.

[3] X. Shao, W. Qu, J. Cao, and Y. Yao, "Static and fatigue properties of the steel-UHPC lightweight composite bridge deck with large Uribs," Journal of Constructional Steel Research, vol. 148, pp. 491-507, 2018.

[4] B. Pei, L. Li, X. Shao, L. Wang, and Y. Zeng, "Field measurement and practical design of a lightweight composite bridge deck," Journal of Constructional Steel Research, vol. 147, pp. 564-574, 2018.

[5] H. Ishii, "Orthotropic steel bridge," 2020, http://www.contecaps.com/business-areas/bridges-rehabilitation/orthotropic-steelbridges.html. 
[6] K.-E. Kurrer, The History of the Theory of Structures: From Arch Analysis to Computational Mechanics, Ernst \& Sohn, Berlin, Germany, 2008.

[7] H. Polk and C. Walker, "Advances and development needs in the structural design of steel box girders for major bridges," Ce/Papers, vol. 1, no. 2-3, pp. 153-164, 2017.

[8] American Institute of Steel Construction, Design Manual for Orthotropic Steel Plate Deck Bridges, American Institute of Steel Construction, New York, NY, USA, 1963.

[9] J. Murakoshi, N. Yanadori, and H. Ishii, "Research on steel fiber reinforced concrete pavement for orthotropic steel deck as a countermeasure for fatigue," Stress: The International Journal on the Biology of Stress, vol. 1, pp. 1-13, 2008.

[10] M. H. Kolstein, Fatigue Classification of Welded Joints in Orthotropic Steel Bridge Decks, Delft University of Technology, Delft, Netherlands, Ph.D. TU Delft, 2007.

[11] F. B. P. De Jong, Renovation Techniques for Fatigue Cracked Orthotropic Steel Bridge Decks, Delft University of Technology, Delft, Netherlands, Ph.D. TU Delft, 2007.

[12] R. Wolchuk, "Lessons from weld cracks in orthotropic decks on three European bridges," Journal of Structural Engineering, vol. 116, no. 1, pp. 75-84, 1990.

[13] Hunan Provincial Communications Planning, Survey \& Design Institution Co., LTD, Report of Ultra-High Performance Light-Weight Composite Deck Application in Longspan Self-Anchored Suspension Bridges, Hunan Provincial Communications Planning, Survey \& Design Institution Co., LTD, Changsha, China, 2017.

[14] R. Walter, J. F. Olesen, H. Stang, and T. Vejrum, "Analysis of an orthotropic deck stiffened with a cement-based overlay," Journal of Bridge Engineering, vol. 12, no. 3, pp. 350-363, 2007.

[15] H. Fang, F. Zou, W. Liu, C. Wu, Y. Bai, and D. Hui, "Mechanical performance of concrete pavement reinforced by CFRP grids for bridge deck applications," Composites Part B: Engineering, vol. 110, pp. 315-335, 2017.

[16] P. Buitelaar, R. Braam, and N. Kaptijn, "Reinforced high performance concrete overlay system for rehabilitation and strengthening of orthotropic steel bridge decks," in Proceedings of Orthotropic Bridge Conference, pp. 384-401, Sacramento, USA, August 2004.

[17] P. Buitelaar, "Ultra thin heavy reinforced high performance concrete overlays," in Proceedings of the 6th International Symposium on Utilization of High Strength/High Performance Concrete, pp. 1577-1590, Leipzig, Germany, June 2002.

[18] R. C. Battista and M. S. Pfeil, "Strengthening fatigue-cracked steel bridge decks," Proceedings of the Institution of Civil Engineers - Bridge Engineering, vol. 157, no. 2, pp. 93-102, 2004.

[19] R. C. Battista and M. S. Pfeil, "Enhancing the fatigue life of Rio-Niteroi bridge's orthotropic steel deck," in Proceedings of the IABSE Symposium, pp. 23-28, Rio de Janeiro, Brazil, August 1999.

[20] F. B. P. De Jong and M. H. Kolstein, "Strengthening a bridge deck with high performance concrete," in Conference Proceedings of 1st Orthotropic Bridge Conference, Sacramento, USA, August 2004.

[21] Z. Hajar, M. Novarin, C. Servant, G. Généreux, D. Przybyla, and D. Bitar, "Innovative solution for strengthening orthotropic decks using UHPFRC: the Illzach bridge," in Proceedings of International Symposium on Ultra-high Performance Fiber-Reinforced Concrete, pp. 117-126, Marseille, France, October 2013.

[22] S. T. De Freitas, H. Kolstein, and F. Bijlaard, "Lightweight reinforcement systems for fatigue-cracked orthotropic bridge decks," Structural Engineering International, vol. 23, no. 4, pp. 458-467, 2013.

[23] J. S. Zhu, Y. G. Wang, J. B. Yan, and X. Y. Guo, "Shear behaviour of steel-uhpc composite beams in waffle bridge deck," Composite Structures, vol. 234, Article ID 111678, 2020.

[24] J.-Y. Wang, J.-Y. Guo, L.-J. Jia, S.-M. Chen, and Y. Dong, "Push-out tests of demountable headed stud shear connectors in steel-uhpc composite structures," Composite Structures, vol. 170, pp. 69-79, 2017.

[25] Z. Zhang and X. Xu, "Static and fatigue behavior of rubbersleeved stud shear connectors as part of field-cast ultra-high performance concrete connections," Materials, vol. 13, no. 10, Article ID 2269, 2020.

[26] Q. Zhao, Y. Du, Y. Peng, C. Xu, and G. Huang, "Shear performance of short channel connectors in a steel-uhpc composite deck," International journal of steel structures, vol. 20, no. 1, pp. 300-310, 2020.

[27] S. Chen, Y. Huang, P. Gu, and J.-Y. Wang, "Experimental study on fatigue performance of uhpc-orthotropic steel composite deck," Thin-Walled Structures, vol. 142, pp. 1-18, 2019.

[28] X. Shao and J. Cao, "Fatigue assessment of steel-UHPC lightweight composite deck based on multiscale FE analysis: case study," Journal of Bridge Engineering, vol. 23, no. 1, Article ID 05017015, 2018.

[29] X. Shao, D. Yi, Z. Huang, H. Zhao, B. Chen, and M. Liu, "Basic performance of the composite deck system composed of orthotropic steel deck and ultrathin RPC layer," Journal of Bridge Engineering, vol. 18, no. 5, pp. 417-428, 2013.

[30] China Communication Press, JTG D60-2015 General Code for Desigh of Highway Bridges and Culverts, China Communication Press, Beijing, China, 2015.

[31] J. Xue, B. Briseghella, F. Huang, C. Nuti, H. Tabatabai, and B. Chen, "Review of ultra-high performance concrete and its application in bridge engineering," Construction and Building Materials, vol. 260, no. 260, Article ID 119844, 2020.

[32] J. Cao, X. Shao, L. Deng, and Y. Gan, "Static and fatigue behavior of short-headed studs embedded in a thin ultrahighperformance concrete layer," Journal of Bridge Engineering, vol. 22, no. 5, Article ID 04017005, 2017. 